\title{
Improving the Quality of e-Commerce Service by Implementing Combination Models with Step-by-Step, Bottom-Up Approach
}

\author{
Hemn Barzan Abdalla, Ge Chengwei, Baha Ihnaini \\ Department of Computer Science \\ College of Science and Technology \\ Wenzhou-Kean University \\ China
}

\begin{abstract}
Commerce, as a hot industry, plays an important role in people's lives. People visit e-commerce websites, check what they want, then click buy, and finally complete the transaction. The developments taking place at the level of electronic services at the global level and the intensification of competition and the increase in the experiences of electronic shoppers, the awareness and understanding of companies of the distinctive characteristics of the population in the region and their purchasing habits has become the most important for companies of e-commerce and services, where it is imperative Companies should keep pace with these developments and provide electronic services via the internet of high quality and efficiency, by focusing on the most important requirements for customer satisfaction, especially in light of the information and technological revolution. However, customers will have an awful experience if they visit crudely made e-commerce websites. Kunst A. (2019, Dec 20) claimed that around a total of $37.4 \%$ of customers complained that they had an awful shopping experience. The reason is that the service quality of e-commerce websites is not up to standard. This research aims to improve the quality of e-commerce service by using the Comprehensive and Referential Combination Model by implementing a Step-by-Step, Bottom-Up approach. Finally, we will recommend improving the quality of e-commerce service in construct and revision ways within parts of this model.
\end{abstract}

Keywords-E-commerce; website; framework; criteria; model; approach; service; quality

\section{INTRODUCTION}

E-commerce is also called electronic commerce or internet commerce. In general, it represents people using the internet to buy and sell commodities or provide clearly priced services in funds and data flows. [6, 23] A computer network is a fundamental tool to make e-commerce achieve its value. More and more people can use the internet to browse the website, which provides the possibility for the promotion of ecommerce websites. From this point of view, e-commerce has great development potential and broad prospects.[15, 16] An E-commerce website enables people to order the goods they want without leaving home, and they can receive the goods delivered by logistics at home. Thus, more people begin to choose e-commerce to choose and purchase their desired products. [17, 18] However, some informal e-commerce websites attract consumers to browse and view through false advertisements or other attractive ways (such as promotion).

As a result, consumers' shopping experience will be very poor, and their precious time will be wasted. Even some formal e-commerce websites will make consumers have a bad shopping experience. The former is due to fraud, extortion, and other bad means. At the same time, the latter is due to rough, lack of consideration of the user interface, inefficient navigation bar, lack of basic description of goods and payment methods without security guarantee, and other adverse factors. These will cause consumers to give up buying products, so there is a high probability that they will not come for a second time. It is very important to establish a basic framework and evaluation scheme for an e-commerce website. [19, 20, 21] The evaluation scheme consists of a series of criteria. Predecessors have not given up this kind of research and put forward their evaluation scheme.

The team of Van Der Merwe (2003) started to begin this type of research in 2003. They proposed to build a new framework and method to evaluate e-commerce websites. In other words, they want to re-establish a credible business principle. [13] They designed three phases to build the framework and method named Level 1, Level 2, and Level 3. They focus on customers, especially the customer buying cycle [13], consisting of recognition, information gathering, evaluation, and purchase completion. They put forward general direction criteria: user interface, navigation bar, content, and degree of website's credibility, technical development. [13] They set 4 criteria groups in each general criteria group. And each criteria group consists of 5 fundamental rules. They use these 100 rules to evaluate famous e-commerce websites (e.g., Amazon, Barnes \& Noble, Exclusive Book, etc.) with the help of correspondence analysis developed by themselves. [13] This has greatly contributed to developing e-commerce websites for systematic evaluation. In addition, the evaluation methods provided by the later research also change due to the changes of the times and different concerns.

In 2016, the group of Watrobski developed a framework for evaluating e-commerce websites called PEQUAL [14]. The author improved the traditional equal method by combining the appropriate model and multi criteria decision analysis (MCDA) which consists of usability, site design, information quality, 
trust, and empathy. [14] They established the framework of the PEQUAL [14] method. First and foremost, they choose the classical EQUAL method and choose one of the website evaluation methods other researchers develop. And then, they use relevant criteria evaluation and other parameters to grade ecommerce websites. It's based on a survey that users contribute. And then, they deal with collecting data by using PROMETHEE [14] method to conform group ranking and individual ranking of e-commerce websites in order to reduce the uncertainty of users filling in the questionnaire. Compared to the previous research, they use different criteria by using different analysis methods. Apart from academic evaluation of e-commerce. [22] Some credible sources also provided some benchmarks and some sets of criteria that are easy to understand to evaluate e-commerce websites for the public who don't know how to use professional analysis methods to evaluate e-commerce websites.

Kogan D. [7] suggested that we can pay attention to content, functionality, authority, and marketing advantages which are elements from e-commerce websites to grade individual e-commerce websites. Also, some websites also gave us several steps to evaluate e-commerce websites in a scientific way. In addition, Burke D.[1], as a famous user experience strategy master, provided 5 criteria for judge whether this e-commerce website is successful or not. Successful e-commerce websites will know how to avoid users register themselves in a complex way. They also consider demonstrating powerful ads and promotions, including a special offer. They also focus on building a strong search engine to ensure that customers will be beneficial to find desirable goods. In a nutshell, the e-commerce industry serves customers to make them have a wonderful shopping experience.

\section{Problem IdENTIFICATION}

How to build an effective model to improve the service quality of an e-commerce website? Can researchers get any inspiration from consumers visiting e-commerce websites and completing a series of transactions? Furthermore, how can researchers use an example to prove the necessity of building this model? How can researchers use the data to demonstrate the effectiveness of our model? Which specific e-commerce website do researchers need to study? What will researchers focus on a specific e-commerce website? What type of tools will researchers use to gather data? The following are some minor problems arising from the main research problems, but these problems basically need to be solved and clearly defined. What makes customers feel like an e-commerce website is good or bad? Is it based on the perceptual visual impact or content reality that researchers can be left behind to complete the process of browsing the website or completing the buying circle [13]? The entrepreneur needs to create an e-commerce website, but how can the entrepreneur create a practical website? What is the definition of utility? Or how can an entrepreneur scientifically create a qualified e-commerce website that can perform its own functions? What is the scope of an e-commerce website? Or the exact duty? Do researchers need to include technology in the evaluation of e-commerce websites? What about including language, culture, other intangible factors into evaluating the e-commerce websites? In addition, how does this research benefit human beings, specifically customers?

The above questions, the main questions need theoretical support, which refers to establish a framework and criteria, and then we compare this model with some former research. The following main questions, which are about the effectiveness of our models, can be answered in the part of research methods. And some of the questions can be answered in a short time. We decide to study the Taobao website, which is a famous ecommerce website in China. And we study how they can improve the quality of this service because we can probably find the link between their strategy and our model. Some of the secondary questions need to be judged by experience, and some can be done by consulting data. For example, we can consult some relevant information by identifying keywords to answer the first question because it's a common background problem. Finally, we can get the answer by presenting some relevant data which is referred from searching websites.

These studies effectively studied how to establish ecommerce websites through a series of criteria, and then at the same time, through clear steps, detailed data of relevant variables to make their established criteria very powerful persuasive. There are other studies that cover not only the establishment of guidelines but also the primary demographic of business sites, namely customers. They take some of the important common behaviors and psychology of customers and make them into core principles, and then combine them with building websites to make them more approachable. Other researchers, however, have looked to the source of the problem and devised designs designed to help companies coordinate their organizational structures and optimize their workforce for market readiness. These results are convincing, but they fail to connect the two most important elements of e-commerce: the company and the customer. And customers can connect through e-commerce sites. Therefore, our research aims to achieve a joint model to solve problems from beginning to end through a series of scientific and organized methods so as to optimize the company's sales situation and customers' shopping environment.

\section{OBJeCt DeterminATION}

Based on this research background, previous studies are to study how to establish a reasonable and complete evaluation mechanism and then use their own data processing methods to evaluate a selected group of e-commerce websites and then process the data. Then the relevant charts are established, and the evaluated websites are compared with each other to get the results. Finally, they give constructive suggestions. Although this will enable some people to obtain references through these studies, which is about getting the evaluation results of popular websites, We should focus on improving the service quality of e-commerce rather than just staying in the evaluation stage. However, an e-commerce website is the facade of the ecommerce industry, so we are committed to solving how to improve the service level of an e-commerce website. 


\section{Methodology}

\section{A. Overview}

First and foremost, our main goal is to improve the quality of the e-commerce website's service. According to the Oxford dictionary definition, service is a system supplying a public need such as transport, communications, or utilities such as electricity and water. The quality of e-commerce service mainly depends on whether consumers think the experience is good or bad after they visit the website, view the content of the website, select goods on the website, and complete the transaction. Therefore, consumers' evaluation after visiting a website is an important index to measure an e-commerce website. How can an e-commerce website's provider improve the quality of the service? We have come up with a solution for this problem. The research is based on that in order to make consumers have a better shopping experience; we need to think about how to improve the serviceability of e-commerce websites and solve the problem from the source. Evaluation can only detect the problem but cannot solve the problem. Therefore, we need to solve this problem with the model composed of framework and criteria for e-commerce websites. We need to modify or design a required e-commerce website based on our established model. This is due to the fact that we need to improve our e-commerce serviceability. So we can focus on how to help owners improve or design their ecommerce websites. An E-commerce website is an owner, a company's facade, and a business card. We have three main phases to construct this solution: building-up, validation, and application for the phase of building-up. We pay attention to and study the consumer's shopping behavior.

The consumer's shopping behavior has five main steps: visit the website, query the goods, view the content of the goods, buy the goods, and pay attention to the logistics trends. Our framework of this model is based on the behavior of customers and established criteria for each part. We can also help build a part of the model by combining an example of a successful e-commerce website. The framework of this model consists of the user interface, searchability, content readability, service safety, website accessibility, future value. We will subdivide each part, namely, criteria. Then we need to prove that our model is practical and reasonable. I will visit the databases of Google Scholar and Kean Library (e.g., ProQuest Central, ProQuest: business) to access some research papers about e-commerce by observing their frameworks and criteria and the data processing methods used.

We even assess the China database (e.g., CNICC) to recently analyze the condition of e-commerce in China. So we can be more informed about this field. We will compare with previous studies to show that evaluation alone is not enough. We need to put this model into action: improve the service level of an e-commerce website. Then, we may distribute the questionnaire and set up questions about consumers. For example, what they want most, what websites they tend to like, and so on. Then we will make suggestions to the owners on how to use our model to modify or design their e-commerce website to improve their service level.

\section{B. Method of Constructing Combination ModelProposed Solution}

1) General working plan: Fig. 1 consists of two main phases: Building-Up and Application. For Building-Up, it has problem identification that states in the introduction part, the construct combination model in Step-By-Step, Bottom-Up Approach with the help of validation, and refine the details about constructing the criteria in each part. For confirmation, it has to find support from customers by using a questionnaire, getting data support from previous scholarly journals, some relevant data to make statements persuasive. The application phase has two ways: redesign and revise by using the combination model we established. Finally, we will give recommendations for each condition.

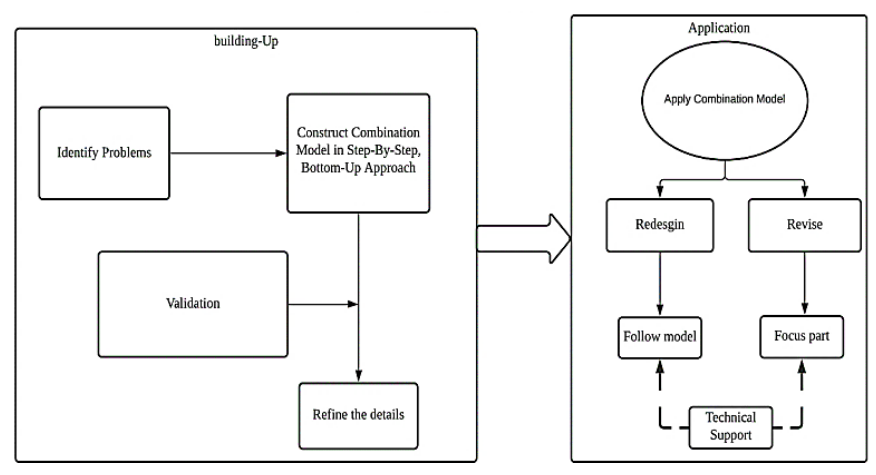

Fig. 1. General Working Plan.

2) Specify method in hierarchy approach: Now we want to construct an efficient method to construct method. The main method we use is called step-by-step, bottom-up, as shown in Fig. 2. We use this method to propose solutions to our research topic. This method is a hybrid method, which is composed of seven sub-methods. Each sub-method carries on the results generated by the previous method. Finally, a complete solution is developed.

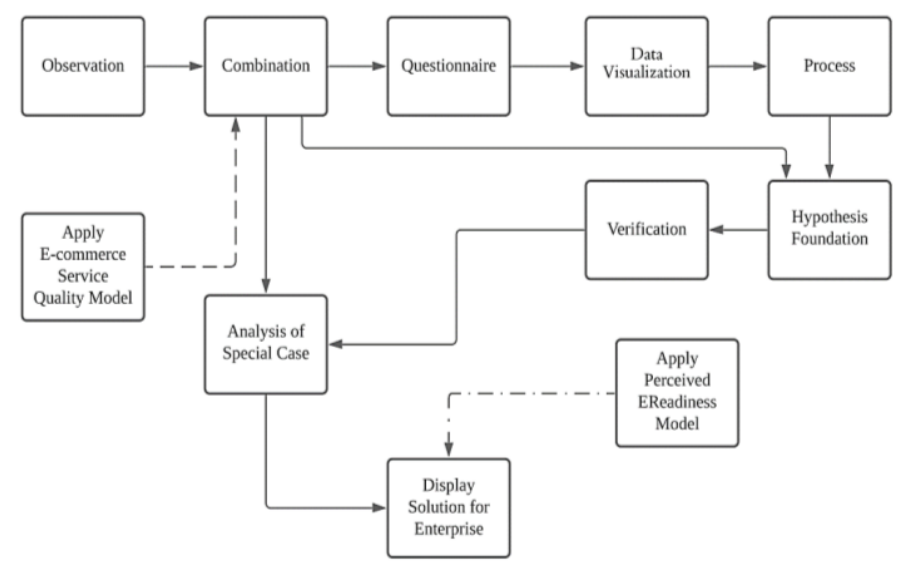

Fig. 2. The Structure of Step-By-Step, Bottom-Up Approach. 
In the below explanation about the structure of the step-bystep, bottom-up approach:

a) Observation - The Behavior of Customers: The customer's shopping behavior has five main steps: visit the website, query the goods, view the content of the goods, buy the goods, and pay attention to the logistics trends. Let's model the behavior of customers who is about to visit a specific website. First and foremost, people initially enter keywords into Google search engine or Baidu search engine to find the website they want to visit. The domain name of some websites is easy to remember, and some people will directly enter the corresponding URL to find it. Usually, popular websites are located on the front page of search results, and they start to click on the website to visit it. Next, they will wait a moment to see the user interface of the e-commerce website. Customers usually visit e-commerce websites to buy what they want. So they will find what they want for the first time, they may seek to use classification screening or the search engine provided by the website to search. Then they will get the details of the product and click buy product to enter the purchase interface. Finally, through secure payment to complete the transaction and after-sales logistics services, finally get the desired goods. The Van's team in 2003 also provided the criteria model of constructing e-commerce websites based on customer behavior shown in Fig. 3 (they called it "buying circle"). This proves that our starting point is correct and consistent with other academic papers establishing e-commerce websites' criteria.

b) Combination - Combine two models with customers' feelings and structure of e-commerce website: The framework and criteria for establishing an e-commerce website are specific because an e-commerce website is a particular thing; customers can see and touch and have visual, intuitive feelings. However, the quality of service is abstract, invisible, and can only be perceived. It is not enough for us to build a good e-commerce website to improve the service quality of ecommerce. Therefore, we need to refer to other studies on the criteria of e-commerce service quality. We are going to combine our model with theirs to produce a new model.

We reference the framework of e-commerce service quality which was worked by Ishak et al. (2021). They used Delphi Method by using questionnaires and giving them to experts to hear their responses, which will be excellent support for constructing criteria in the e-commerce service. Here is the result from Ishak's team, as shown in Fig. 4. They provide what the e-commerce industry can do for customers and what kind of experience customers need: reliability, responsiveness, assurance, empathy, and tangible ways. However, they established a model based on the view of customers. So we want to refine this model and create another model based on the structure of e-commerce websites and combine them from different perspectives. We want to make more details in each part associated with customer behavior. We also refined some subcriteria and category them into more complex parts, which will list in the result section.

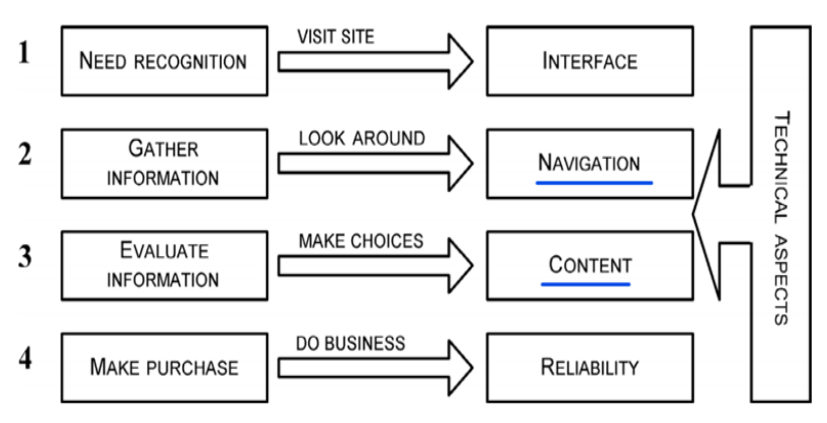

Fig. 3. Customer behavior [13].

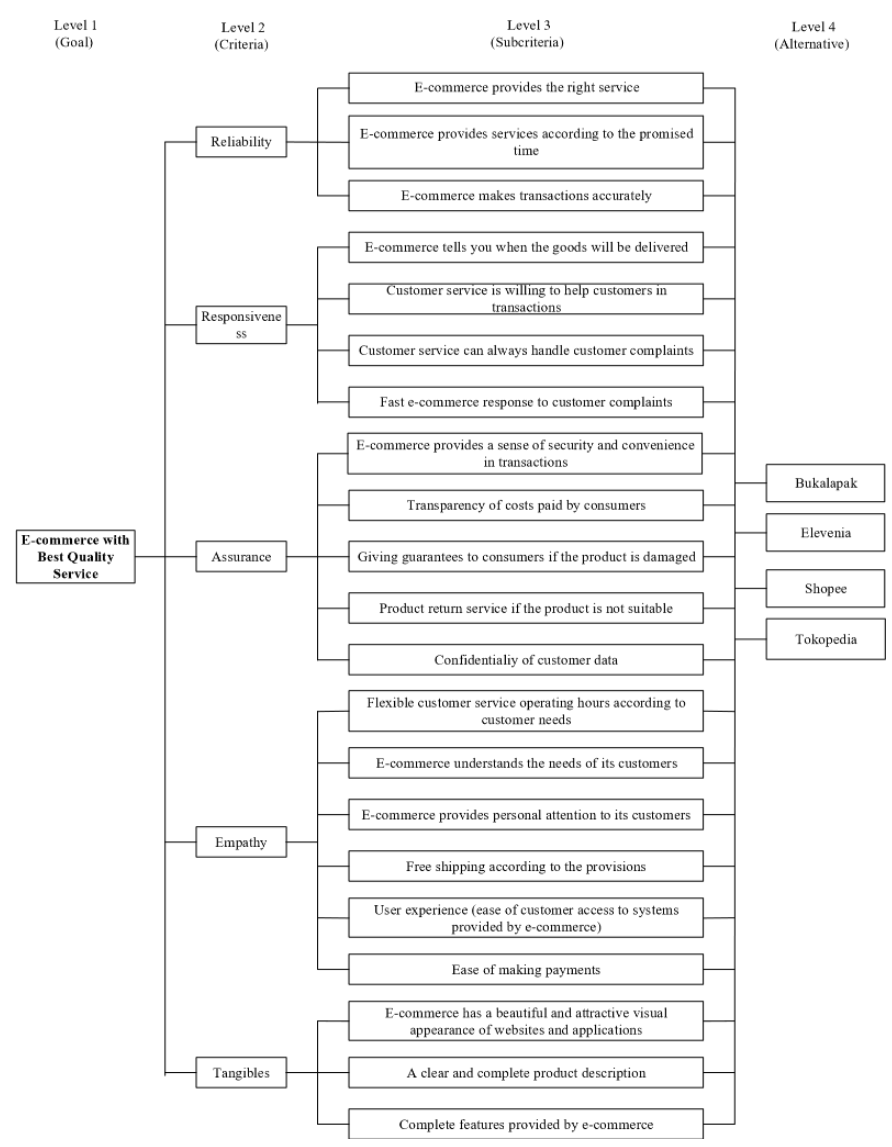

Fig. 4. The Framework of e-commerce Service Quality [5].

c) Questionnaire - prepare for building criteria of ecommerce website model: The questionnaire can get the public's view of e-commerce and help modify the model. And through the response of the people, we can see whether our research is on the right track. We use a questionnaire to verify whether our model has a mass basis and is widely accepted by the public. The questionnaire was designed for adults over 18 years old who are potential customers. Forty-three people were invited to fill in the questionnaire, of which three were not completed, which was invalid. So there are 40 valid questionnaires. Among them, there are 20 males and 20 females, and college students account for the most, accounting for 75\%. The remaining 23-30 years old, 31-40 years old, and $51-60$ years old accounted for $12.5 \%, 2.5 \%, 5 \%$, and $5 \%$. Here are Table I shows the results from the questionnaire. 
TABLE I. RESULT FROM QUESTIONNAIRE

\begin{tabular}{|l|l|l|l|l|l|l|}
\hline Reaction & $\begin{array}{l}\text { Total } \\
\text { Disagree }\end{array}$ & Disagree & $\begin{array}{l}\text { non- } \\
\text { agree or } \\
\text { disagree }\end{array}$ & agree & $\begin{array}{l}\text { total } \\
\text { agree }\end{array}$ & Total \\
\hline 1 & 0 & 1 & 8 & 10 & 21 & 40 \\
\hline 2 & 0 & 4 & 9 & 9 & 18 & 40 \\
\hline 3 & 0 & 3 & 9 & 14 & 14 & 40 \\
\hline 4 & 0 & 0 & 13 & 12 & 15 & 40 \\
\hline 5 & 0 & 1 & 9 & 15 & 15 & 40 \\
\hline 6 & 0 & 2 & 6 & 14 & 18 & 40 \\
\hline 7 & 0 & 1 & 8 & 8 & 23 & 40 \\
\hline 8 & 0 & 0 & 9 & 6 & 25 & 40 \\
\hline
\end{tabular}

d) Structure of Questionnaire

1) You want to find the website you want to visit through keywords quickly.

2) If the website you visit doesn't respond quickly, you will feel impatient.

3) You want to see an attractive user interface (the first page you see on the site).

4) You tend to visit a creative website that gives you a visual experience.

5) If you can't find what you want through the website's search engine, you will feel distressed.

6) You want the site to provide classification options to help you search for the items you want.

7) You tend to visit websites with secure payment methods (Alipay, WeChat).

8) You tend to visit a website that provides after-sales service.

e) Data Visualization: The data in Fig. 5 obtained shows that $77.5 \%$ of the respondents hope to get the website they want quickly through keywords. $67.5 \%$ said they would be impatient with websites that can't respond quickly, while $70 \%$ wanted to see attractive user interfaces. $67.5 \%$ of people want to have a visual experience website. Nearly $75 \%$ of the people feel distressed. If they can't find the products they want by using the website's search engine, $80 \%$ of the people also hope that the e-commerce website can provide classification options to help them view the products. Nearly $80 \%$ (77.5\%) love Alipay and WeChat's payment sites, and the percentage of people also hope that e-commerce can provide customer service.

f) Hypothesis Foundation - build a hypothesis model of criteria of e-commerce website: Based on the results obtained by the previous face method and our experience of browsing popular e-commerce websites (such as Taobao and Jingdong) and shopping experience, we provide a hypothesis model to combine with the previous research abstract model (combination process).

The framework of an e-commerce website, as shown in Fig. 6, consists of the user interface, readability, searchability, service safety, website accessibility, future value. This is based on the behavior of customers. The user interface is the consumer's first impression of an e-commerce website, which affects their actions. For readability, it represents the degree of customers understanding the product's basic information on an e-commerce website. For searchability, it represents the search capability of an e-commerce website. For service safety, it reflects the security level of the e-commerce website. For website accessibility, it reflects the technology level of this ecommerce website. Finally, for future value, this represents the degree to which the site has plans and goals for the organization. Table III demonstrates the visual of this framework. Here is the framework of the e-commerce website in a concise version.

The criteria of the e-commerce website model, as shown in Fig. 7, demonstrate the subcriteria of these six main parts in construct an effective e-commerce website. It's another version of the framework of an e-commerce website in a more complex way.

Then we combine our established model with the framework of e-commerce service quality, as shown in Fig. 4, by connecting with two perspectives: customers' individual emotions and the structure of e-commerce website to construct the combination model. This can provide a good blueprint for e-commerce enterprises after they make a foundation for themselves. They connected with each other by using the problem domain approach, which means that they will map (dash line) with each other if both blocks discuss the same field in the framework.

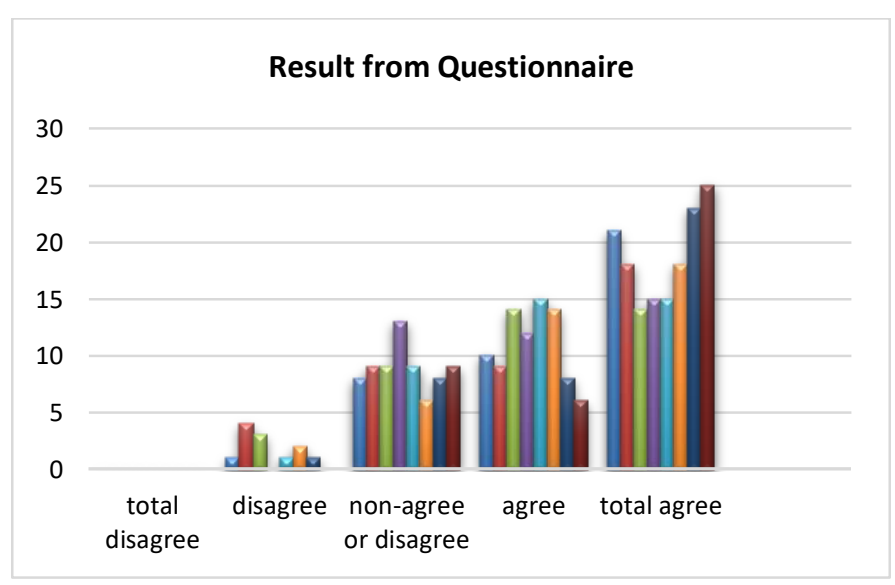

Fig. 5. Result from Questionnaire in Histogram.

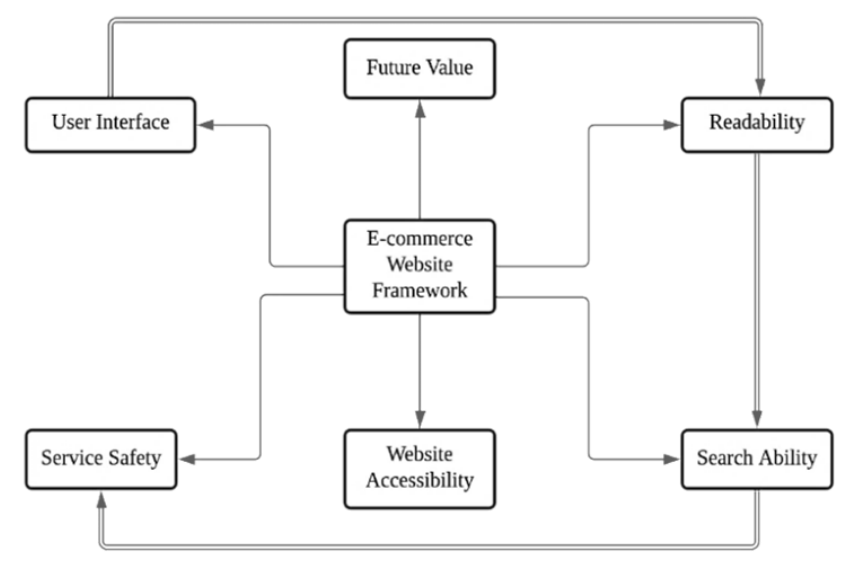

Fig. 6. Framework of E-commerce Website. 


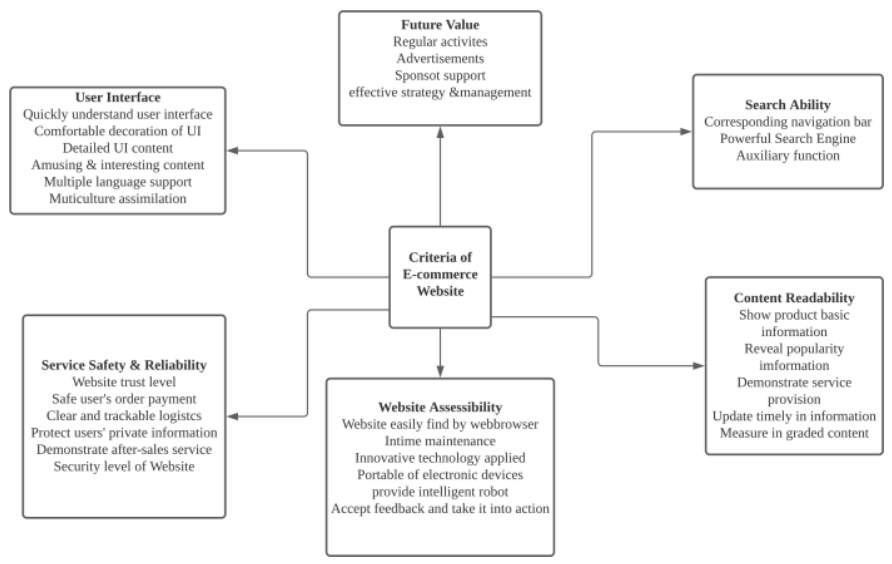

Fig. 7. Criteria of E-commerce Website.

g) Verification of Combination of Model of Ecommerce: Based on the above, we start from the consumer behavior, improve a research model, establish their model, and then combine, and finally get a more comprehensive and valuable model. We have also adopted a series of scientific and practical methods. The framework of criteria of the ecommerce website model consists of the user interface, searchability, content readability, service safety and reliability, website accessibility, and future value. We find that we are supported by Sharma and Aggarwal (2019) 's work because they built the model of successful e-commerce based on the hypothesis as shown in Fig. 8, which consist of five main parts to determine the success of e-commerce service with the help of Exploratory Factor Analysis (EFA) method. They also verify it by using Partial Least Square -Structural Equation Modeling(PLS-SEM) [11] by providing loadings, Cronbach's $\alpha$. And we consider the value of Cronbach's $\alpha$ for each variable in Table II. This value can be regarded as good if they fall between 0.8 and 0.9. From Table II, we can find that each variable can be considered a credible measurement of ecommerce success. All these variables discussed similar topics and included some functions that we used in our hypothesis model of e-commerce website criteria. So our model is greatly supported by this credible data.

h) Analysis of One Special Case - Study interviews from Alibaba: Leavy, B. (2019, Match 18) interviewed Zengming, who is a famous Alibaba strategist. He asked about Alibaba's milestones, a series of turning points, the impact on China's industry, the application of intelligent commerce, the model of mutual cooperation in the network, and the final strategic positioning. Zengming answered these questions in detail. From this interview, we mainly focus on Alibaba's business scope and strategic positioning. The business scope of Alibaba is core business, cloud computing, logistics services, microfinancial services [9] mainly.

They also have other initiative actions such as entertainment on the internet. From this, we can think that Taobao, tmall, financial services, and rookie are all based on these kinds of business scope. From this professional interview, we can find that Alibaba initially set up a goal for small and micro enterprises to have their own position and influence. It is a B2B business platform for all other franchised enterprises. Alibaba has been doing this business for a period of time, accumulated some capital, and gained particular strength. Then, in order to prevent other enterprises from seizing market share, they made some adjustments to their goals, such as creating a Taobao website which is a business platform for major e-businesses to join in and allow them to carry out legal business activities on their own platform and making tmall [9] separate and independent, in order to speed up the penetration of China's market.

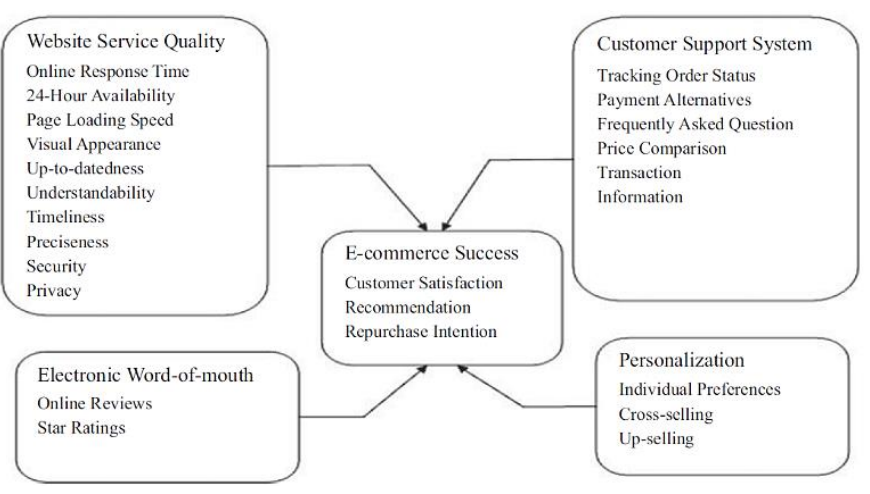

Fig. 8. Model of Successful E-commerce [11].

TABLE II. Five Big VARIABLES To DETERMINE THE SUCCESS OF ECOMMERCE [11]

\begin{tabular}{|c|c|c|c|c|}
\hline Variable & hems & Loadings & Cronbach's a & $\mathrm{CR}$ \\
\hline \multirow[t]{10}{*}{$\begin{array}{l}\text { Website service quality } \\
\text { (WSQ) }\end{array}$} & WSQ1 & 0.66 & 0.805 & 0.80 \\
\hline & WSQ2 & 0.756 & 0.799 & \\
\hline & WSQ3 & 0.493 & 0.802 & \\
\hline & WSQ4 & 0.496 & 0.808 & \\
\hline & WSQ5 & 0.598 & 0.802 & \\
\hline & WSQ6 & 0.604 & 0.802 & \\
\hline & WSQ7 & 0.433 & 0.804 & \\
\hline & WSQ8 & 0.465 & 0.802 & \\
\hline & WSQ9 & 0.418 & 0.808 & \\
\hline & WSQ10 & 0.349 & 0.806 & \\
\hline \multirow[t]{6}{*}{$\begin{array}{l}\text { Customer support } \\
\text { system (CSS) }\end{array}$} & CSSI & 0.502 & 0.803 & 0.72 \\
\hline & CSS3 & 0.334 & 0.807 & \\
\hline & CSS3 & 0.506 & 0.801 & \\
\hline & CSS1 & 0.709 & 0.806 & \\
\hline & CSS5 & 0.559 & 0.812 & \\
\hline & CSS6 & 0.497 & 0.803 & \\
\hline \multirow[t]{3}{*}{ Personalization (PER) } & PER1 & 0.798 & 0.822 & 0.76 \\
\hline & PER2 & 0.787 & 0.820 & \\
\hline & PER3 & 0.859 & 0.815 & \\
\hline \multirow[t]{2}{*}{$\begin{array}{l}\text { Electronic word-of- } \\
\text { month (EWOM) }\end{array}$} & EWON11 & 0.820 & 0.810 & 0.85 \\
\hline & EWOM2 & 0.798 & 0.808 & \\
\hline \multirow[t]{3}{*}{$\begin{array}{l}\text { ecommerce system } \\
\text { success (ISS) }\end{array}$} & ESS1 & 0.624 & 0.806 & 0.78 \\
\hline & ESS2 & 0.791 & 0.809 & \\
\hline & ESS3 & 0.709 & 0.803 & \\
\hline
\end{tabular}


As time goes on, Alibaba hopes to achieve something in other fields, such as finance and technology. They created two companies: Alipay and cloud computing. Among them, Alipay has a profound impact on China's payment system. Among them, Alipay had a profound effect on China's payment system. People use Alipay to pay for goods, make commercial loans, and transfer accounts. Alipay even contracted for various platforms' two-dimensional code scanning services, such as providing health codes to provide passage and implementing epidemic prevention policies. Or use two-dimensional code to go shopping, daily behavior. Taobao is an e-commerce website whose essential function is to provide customers with online shopping services. Among them, he innovated away: at that time, it was very advanced. Taobao provided leasing services for businesses, that is, let businesses open shops online. Companies can rent a physical store in the urban area to sell goods without high rent. They only need to use the platform provided by Alibaba to complete their business online. From this point of view, they are mutually beneficial and win-win on the premise that there is no relationship between exploitation and exploitation. At the same time, Zengming also said in the dialogue that they have an intelligent business expansion. Through the internet and big data, customer companies are combined to operate together. To find the corresponding laws and survive in this cruel market.

Most importantly, Alibaba is very clear about its position. They know what they want to do and the significance of doing it. They put forward the theory of point, line, and surface [9], and they take on the role of the line as the provider of infrastructure. And they are bigger and stronger, which shows that they have done an excellent job in the part of the line. So they can succeed and have the energy to do other business sectors. They also mentioned the importance of intelligence data combined with the internet to provide better service for customers. They focus on making customers have better ecommerce service and provide a smooth communication approach between customers and business. Therefore, ant financial services are born to help provide loans to promote the sustainable development of the economy. As shown in Table III, Alibaba's strategies demonstrate their theory in detail from four main aspects: feature, point, line, and plane.

i) Construct solutions for e-commerce enterprise: First and foremost, e-commerce enterprises should determine what industry they belong to. The distribution of the e-commerce industry in China, as shown in Fig. 9, demonstrated Chinese ecommerce industry distribution. We can find that clothing, shoes, and hats, textile and chemical fiber, agriculture, forestry and animal husbandry, digital home appliances, mechanical equipment, chemical plastics, food, sugar and wine, building materials, hardware tools, medical and pharmaceutical products account for a high proportion to a low balance. These are shown in Fig. 9 clockwise, which started from clothing and shores. And others industry occupies about $31.90 \%$. It's not difficult to find that many industries are related to ecommerce. What kind of products do enterprises need to provide depends on the company's technology type and development direction? Companies need to pay attention to which industries have good development potential and the broad market. To pay attention to these industries and prepare for the transformation of these industries.

TABLE III. The Three STRATEGIC Positions IN A Business ECOSYSTEM [9]

\begin{tabular}{|c|c|c|c|}
\hline \multicolumn{4}{|c|}{ Strategic Position } \\
\hline Feature & Point & Line & Plane \\
\hline $\begin{array}{l}\text { Value } \\
\text { proposition } \\
\text { or service }\end{array}$ & $\begin{array}{l}\text { Selling a function or } \\
\text { capability }\end{array}$ & $\begin{array}{l}\text { Creating a } \\
\text { product }\end{array}$ & $\begin{array}{l}\text { Connecting related } \\
\text { parties }\end{array}$ \\
\hline $\begin{array}{l}\text { Competitive } \\
\text { advantage }\end{array}$ & Expertise & $\begin{array}{l}\text { Value, cost, } \\
\text { and efficiency }\end{array}$ & $\begin{array}{l}\text { Matching } \\
\text { efficiency }\end{array}$ \\
\hline $\begin{array}{l}\text { Organization } \\
\text { al capabilities }\end{array}$ & $\begin{array}{l}\text { Simple; no complex } \\
\text { operations }\end{array}$ & $\begin{array}{l}\text { Streaming } \\
\text { and } \\
\text { optimizing } \\
\text { workflows }\end{array}$ & $\begin{array}{l}\text { Designing systems } \\
\text { and institutions to } \\
\text { mediate } \\
\text { relationships }\end{array}$ \\
\hline Core strategy & $\begin{array}{l}\text { Advance into the } \\
\text { next rising plane and } \\
\text { find one's niche in a } \\
\text { fast-growing line }\end{array}$ & $\begin{array}{l}\text { Use the } \\
\text { resources of } \\
\text { robust planes } \\
\text { to incorporate } \\
\text { strong points }\end{array}$ & $\begin{array}{l}\text { Enable the growth } \\
\text { of points and lines }\end{array}$ \\
\hline $\begin{array}{l}\text { Web-celeb } \\
\text { analogy }\end{array}$ & $\begin{array}{l}\text { Factories, clothing } \\
\text { designers }\end{array}$ & Ruhan & Taobao, Weibo \\
\hline
\end{tabular}

\section{China's E-commerce Industry Distribution}

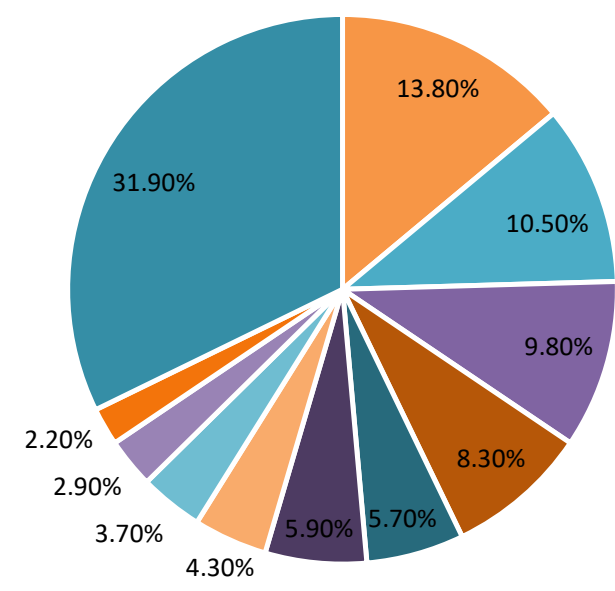

- clothing and shoes

- Textile and chemical fiber

- Agriculture, forestry and animal husbandry

- digital household appliance

- mechanical equipment

- Chemical plastic

- Grain/ Food/ Sugar and Wine

- Building materials

- hardware

- Medical treatment

- others

Fig. 9. Chinese E-commerce Industry Distribution [3]. 


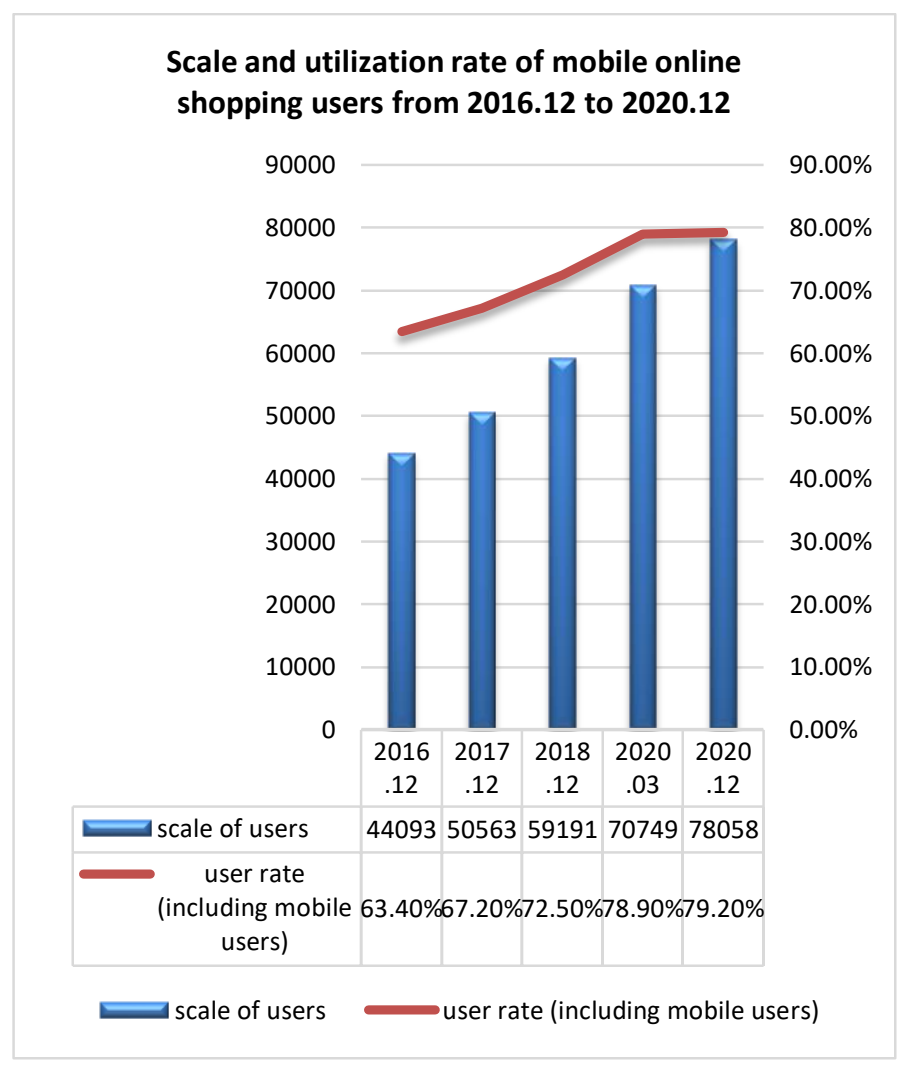

Fig. 10. Scale and Utilization Rate of Mobile Online Shopping users from 2016.12 to 2020.12 [2].

Furthermore, China's e-commerce sector is still showing a good development trend in China. From the condition of users using electronic devices as shown in Fig. 10, we find that the Internet-scale is increasing year by year. By 2020 , the ranking will reach 780.58 million people, and about $80 \%$ of users will use online shopping. Internet in China is still in progress, promotion. The market scale is gradually expanding. As shown in internet listed companies as shown in Fig. 11, 12.6\% of the listed enterprises are e-commerce enterprises. It shows that many enterprises still choose the field of e-commerce. From this, we can see that e-commerce in China has a good development prospect and is still creating a new high.

Next, Enterprises need to know what kind of customers they serve, so they are roughly divided into four categories according to customer types. They are B2C (business to customer), B2B (Business-to-Business), C2C (Consumer To Consumer), B2G (business-to-government), respectively. And $\mathrm{B} 2 \mathrm{C}$ and $\mathrm{B} 2 \mathrm{~B}$ are the main forms of e-commerce enterprises in China. Companies need to choose partners according to their products or services to determine the type of e-commerce company. The group of Tan also used the Perceived eReadiness Model, as shown in Fig. 12, which will help them analyze the situation of the e-commerce industry in
China. [12] Based on this model, they have made corresponding improvements and put forward the factors that affect the development of e-commerce in China. They also used the nine most essential variables (factors) they considered to measure their degrees of reliability by using cronenbach alpha, as shown in Table IV, which measures the reliability. The nine variables are awareness (A), Business Resources (BR), Commitment (C), Governance (G), Government eReadiness (GVeR), Human Resources (HR), Market forces eReadniess (MFeR), Supporting industries eReadiness (SIeR), and Technological resources (TR). [12] The variable of cronenbach alpha will be higher, which shows that it tends to be more favorable for e-commerce development. However, human resources may not be considered as a negative part in China of 2020. In addition, Fig. 10 shows that about 78058 million people have electronic devices to surf on internet in 2020. This may be much helpful to improve the development of human resources. Tan (2007) also proved that this model is appliable in China, as shown in Fig. 8. This model provides an excellent structure even for business starters who want to build a company with other people. This is because this model demonstrates some essential elements in building a perceived or hardworking organization. This model gave the standard to e-commerce enterprises about the quality of employees, executors, strategies, external forces, practical enterprise's managing structure. In concrete, this model puts forward the following requirements for the company: the level of employees and the reserve of professional knowledge need to meet the standards to be competent for their work. Companies need a real-time view of current events, external industry information, and their field and e-commerce field to predict future development. Prepare for transformation and revision. At the same time, this model also puts forward requirements for employees' work experience and the application of electronic aids. Especially for strategic planning, employees at the forefront of the field are essential. At the same time, it also puts forward a series of essential requirements for decisionmakers, requiring them to have a clear strategic plan, which can be related to previous interviews, because Alibaba is the leader of B2B in China. This model can be combined with Alibaba's strategy for reference. At the same time, this model also requires to be aware of external forces. For example, government policies, administrative decrees, preferential policies, market changes (changes in demand), and cooperation between financial and trust institutions. Enterprises can use this model to initially form the company structure, thinking direction, and employee type. And then, they can move to the production of the website as the company's facade, portal, the first step of customer and enterprise communication. Then we use this model to combine this model, which is about applying this model into the hypothesis model combined e-commerce service quality's model, strategy in one particular case into a more comprehensive and referential combination model as shown in Fig. 12. 


\section{Distribution of Internet listed companies}

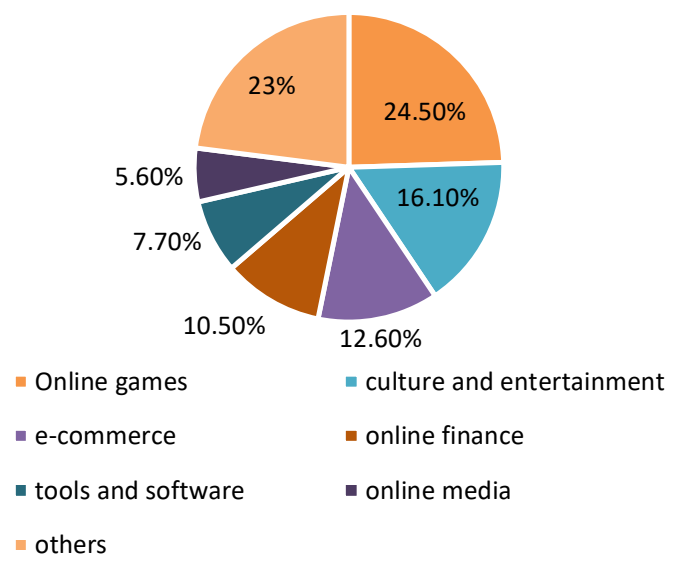

Fig. 11. Distribution of Internet Listed Companies (China Internet Network Information Center) [2].

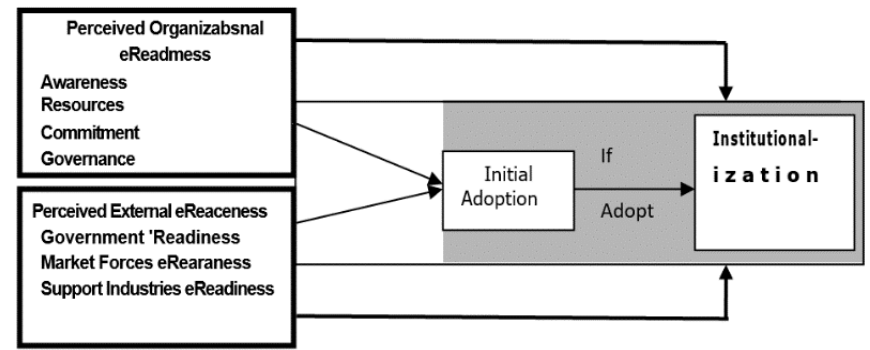

Fig. 12. Perceived eReadiness Model Framework [12]

TABLE I. MEASURE OF RELIABILITY IN EACH TERM OF PERCEIVED EREADINESS MODEL [12]

\begin{tabular}{|l|l|}
\hline Instrument reliability & \\
\hline & Cronebach alpha \\
\hline A & 0.91 \\
\hline BR & 0.70 \\
\hline C & 0.91 \\
\hline G & 0.92 \\
\hline GveR & 0.78 \\
\hline HR & 0.59 \\
\hline MfeR & 0.86 \\
\hline SieR & 0.83 \\
\hline TR & 0.82 \\
\hline
\end{tabular}

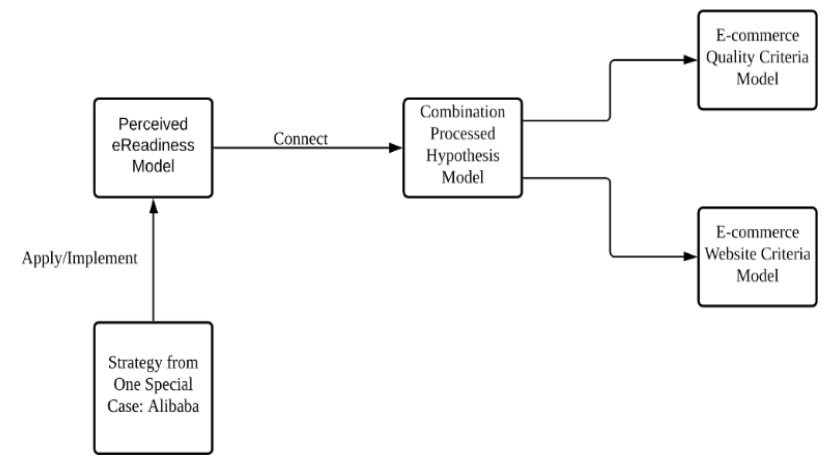

Fig. 13. Comprehensive and Referential Combination Model.

\section{RESUlT}

The Comprehensive and Referential Combination Model as shown in Fig. 13, in the last part, which consists of the Perceived eReadiness Model as shown in Fig. 12, applied strategy as shown in Table III, Combination Processed Hypothesis as shown in Fig. 4 and Fig. 7, which are mapped in the domain). This model has been proved to be reasonable, supported by data, and comes from scholarly journals. Next are the detailed versions of the e-commerce website criteria model.

1) Part of Combination of Hypothesis Model - Details of criteria of e-commerce website.

a) User Interface

- Customers understand the user interface quickly When browsing the website. a. Website has tutorial guidance. b. The user interface is simple and easy to understand.

- Customers feel comfortable in the decoration of the user interface a. font size b. shape c. font color $d$. the suitability of background color, typesetting.

- The content of the user interface is detailed. a. Related to the theme of the website $b$. The contents are arranged in an orderly and regular way. c. There exist pictures to help explain the contents and other auxiliary materials d. There is enough information to enable customers to have a complete understanding of the product.

- The contents are interesting, a. cartoon elements or video provided or any other visual dynamic aids b. List recommended items shown in the user interface. c. Provide Popular current products.

- Support multiple languages and accept the local culture.

b) Search Ability

- There is a corresponding navigation bar on the ecommerce website. a. it's conspicuous so that users can easily find it. b. There is a classification or a subdivision of the classification. c. There is a special effect to display the column subdivided under the classification.

- Provides a powerful search engine. a. Users can find the goods they want by entering keywords. b. accurate 2 . valid links (user can access these links).

- Auxiliary function a. When inputting text into the search box, there is help content display. b. The speed of search result.

c) Content Readability

- Provide the product's basic information: pictures, size, type, price, inventory surplus, shipper and address, price of each piece (unit).

- Provide the popularity information: monthly sales volume, the number of people who view and buy, comment information.

- Provide the service: seven days no reason to return the goods, customer service consultation, 
- Timeless of the product information a. Update regularly. b. No grammatical errors, typos.

- Graded content: ensured that minors could not search for adult contents.

\section{d) Service Safety and Reliability}

- The trust level of the website, a. the last line of the user interface, has key information: company information, address, telephone, zip code, and copyright. b. There is a certificate of business granted by the state and a series of trust licenses.

- The user's order payment approach is safe or even multiple, including Apple Pay, WeChat, Alipay.

- The logistics are precise. a. the transparency of the delivery mode of goods b. Easy to grasp the direction (e.g., using GPS and graph).

- Promise to protect customers' personal information from leakage. a. protects the customers' filling orders. b. Protect the process of the transaction.

- Perform product after-sales service. a. Support comments from buyers. b. 24 hours or most of the time, customer service consultation is available. c. Provide suggestion channels: telephone contact information provided, email feedback. d. Provides real-name registration.

- The security level of the website (HTTPS).

e) Website accessibility

- Users can easily find the site from various search engines.

- Intime maintenance $\log$ a. Update records. b. Update relevant personnel.

- New technology is used in the website. a. The speed of opening the website: network response, display interface speed. b. A working database: record the relevant information of various commodities, which information can change in real-time.

- The availably of computers and mobile phones a. Succeed in displaying in other electronic products display screen (compatibility).

- Design intelligent robot feedback to help answer questions.

f) Future Value: An E-commerce website has regular activities, advertisements, sponsor support, organized and effective strategy, and management.

2) Validation for Established Model

a) Find Support from Customers: According to questionnaire data, we find that nearly $75 \%$ of them agree with our perspective of establishing the framework and criteria on average. This means that our starting point is correct, and we are suitable to analyze the customer's behavior and what they want. b) Theoretical Support from Previous Research: Apart from we mentioned Data support in the previous, here is the theoretical backing of prior research. Van Der Merwe's team (2003, Dec 1) quoted other people's opinions about the evaluation website; they think that the framework and criteria should be established from the customer's buying circle. Next, $\mathrm{Lu}$ J. (2003) provided a way of building a company assessment framework, website capabilities, and customer assessment. [10] They set 8 groups to establish criteria for each part. In a way, part of his research is similar to our study because they also consider the factors of customers.

What's more, Hasan et al. (2013) got assistance from three other research which is to use framework and criteria to evaluate e-commerce websites. [4] They even observed a series of actions generated by users using e-commerce websites, which they recorded in real-time. In short, they kept their behavior by having the subjects perform the same task. This is similar to our study of customer behavior. These studies provide great theoretical help for our research.

\section{RECOMMENDATION}

Enterprises need to go through the first step in the Comprehensive and Referential Combination Model. Then they can go through the next step, which is about designing ecommerce websites that are parts of a combination of hypothesis models. Companies that want to build an ecommerce website and carry out online shopping business use this model to design user interface, search engine, commodity content interface, and payment interface. The content of each criterion can be used as a reference to remind the creator to consider joining or make corresponding fine-tuning as needed. After the design, they invite some volunteers or experts to put forward suggestions and opinions on this website. Then release and open users to enter the website for testing and make corresponding adjustments according to the feedback. If the company has completed the production of the website, the evaluation is given by testers after testing the website is not ideal. Then you can refer to the model for comparison and add or modify the missing part. To improve the service level. Also, the company can refer to Alibaba's operation mode and connect the company's information with customers and partners to ensure the timely transmission, delivery, and exchange of information. At the same time, according to current events and market changes, we should make corresponding adjustments to the strategic plan and clarify our role in the whole business field, that is, what we can provide, what we want to do, and the purpose of doing these things so that these can increase the level of future value.

\section{CONCLUSION}

The significance of our results is to solve the problem of improving the service quality of e-commerce websites by using the Comprehensive and Referential Combination Model by implementing a Step-By-Step, Bottom-Up approach that constructed efficiently. In the result, we also suggest how to use this model, which is in the recommendation section.

Although this study proposes solutions and processes to improve the service quality of e-commerce websites and has specific theoretical and public support, it lacks experts to verify 
the design in person. We provide what we need to pay attention to and what kind of functions. However, we are lack of detailed quantitative and detailed description of each criterion. For example, under what circumstances and how many large fonts are used. This requires a lot of work and some professionals to investigate and analyze e-commerce websites in various fields.

Moreover, we need to make an overall analysis of this joint model. For example, we need to find out the related problems for this model and then distribute the questionnaire to experts. Because this model involves many aspects and many questions need to be prepared, it is inappropriate to distribute this questionnaire to the internet. The public does not have professional knowledge in this field. Therefore, the right person to fill in the questionnaire is someone familiar with the field of e-commerce. We may move towards this in the future. These will take a lot of time. If there is time support, the instrument and the corresponding helpers will provide support. This research may continue in the future or even develop in other directions, for example, using this model to evaluate popular websites for e-commerce research. We can also keep the original order and optimize the combination model's design, which contains several models, by implementing more relevant variables.

\section{ACKNOWLEDGMENT}

The authors gratefully acknowledge the financial support from Leading Talents of Provincial Colleges and Universities, Zhejiang-China(\#WB20200915000043). With Wenzhou-Kean University.

\section{REFERENCES}

[1] Burke D. (2015, May). 5 Criteria for a Successful eCommerce Website Avoiding mistakes that would be embarrassing in a retail store. Retrieved from https://www.getfused.com/blog/posts/5-criteria-for-asuccessful-ecommerce-website-87

[2] China Internet Network Information Center (2021, Feb. 23). The 47th statistical report on the development of Internet in China. Retrieved from

http://www.cnnic.net.cn/hlwfzyj/hlwxzbg/hlwtjbg/202102/P0202102033 34633480104.pdf

[3] Foresight Industrial Research Institute. (2016, Apr., 21). Market Outlook and Investment Strategy Planning Analysis Report of China ECommerce Industry (2016-2021). Retrieved from https://bg.qianzhan.com/report/detail/459/160421-9a14f4f1.html

[4] Hasan, L., Morris, A., \& Probets, S. (2013). E-commerce websites for developing countries - a usability evaluation framework. Online Information Review, 37(2), 231-251. doi:http://dx.doi.org/10.1108/OIR10-2011-0166

[5] Ishak, A., Ginting, R., \& Wanli, W. (2021). Evaluation of e-commerce services quality using Fuzzy AHP and TOPSIS. IOP Conference Series: Materials Science and Engineering, 1041(1), 012042. https://doi.org/10.1088/1757-899x/1041/1/012042

[6] Jenn Vande Zande. (n.d.). What is e-commerce? Definition, benefits, examples. Retrieved from https://www.the-future-ofcommerce.com/2020/01/19/what-is-e-commerce-definition-examples/

[7] Kogan D. (2013, July 24). 8 Ways To Evaluate Your eCommerce Website. Retrieved from https://www.1digitalagency.com/8-ways-toevaluate-ecommerce-website/
[8] Kunst A. (2019, Dec 20). U.S. online shoppers with negative shopping experiences 2017.2 Retrieved from https://www.statista.com/statistics/705252/shopping-experience-ofonline-shoppers-in-the-us/

[9] Leavy, B. (2019, March 18). Alibaba strategist ming zeng: "smart business" in the era of business ecosystems. Strategy and Leadership. Emerald Group Publishing Ltd. https://doi.org/10.1108/SL-01-20190006

[10] Lu, J. (2003). A model for evaluating E-commerce based on Cost/Benefit and customer satisfaction. Information Systems Frontiers, 5(3), $265 . \quad$ Retrieved from https://kean.idm.oclc.org/login?url=https://www.proquest.com/scholarly -journals/model-evaluating-e-commerce-based-on-costbenefit/docview/232037789/se-2?accountid=11809

[11] Sharma, H., \& Aggarwal, A. G. (2019). Finding determinants of ecommerce success: A PLS-SEM approach. Journal of Advances in Management Research, 16(4), 453-471. doi:http://dx.doi.org/10.1108/JAMR-08-2018-0074

[12] Tan, J., Tyler, K., \& Manica, A. (2007). Business-to-business adoption of eCommerce in China. Information and Management, 44(3), 332-351. https://doi.org/10.1016/j.im.2007.04.001

[13] Van Der Merwe, R., \& Bekker, J. (2003, December 1). A framework and methodology for evaluating e-commerce Web sites. Internet Research. https://doi.org/10.1108/10662240310501612

[14] Watrobski, J., Ziemba, P., Jankowski, J., \& Wolski, W. (2016). PEQUAL-E-commerce websites quality evaluation methodology. In Proceedings of the 2016 Federated Conference on Computer Science and Information Systems, FedCSIS 2016 (pp. 1317-1327). Institute of Electrical and Electronics Engineers Inc. https://doi.org/10.15439/2016F469

[15] Teo, T.S.H. \& Liu, J. (2007). Consumer trust in e-commerce in the United States, Singapore and China. Omega, 35(1):22-38.

[16] Sun, P. C., Luo, J. J., \& Liu, Y. L. (2010, November). Perceived Risk and Trust in Online Group Buying Context. In Information Management, Innovation 323 Management and Industrial Engineering (ICIII), 2010 International Conference on (Vol. 3, pp. 660-663). IEEE.

[17] Sulaiman, A., Jaafar, N.I., \& Kadam, P. (2005). Factors affecting online purchasing among urban internet user sin Malaysia. Fourth International Conference on eBusiness, November 19-20. Bangkok, Thailand.

[18] Stewart, D. W. (1981). The application and misapplication of factor analysis in marketing research. Journal of Marketing Research, 18(1), 51-62.

[19] Saibaba, G., and P. Vaidya Sanivarapu. "Developing an Userfriendly Online Shopping Web-Site." Indonesian Journal of Electrical Engineering and Computer Science 12, no. 3 (2018): 1126-1131.

[20] Al-Qirim, N., 2007. The adoption of eCommerce communications and applications technologies in small businesses in New Zealand. Electronic Commerce Research and Applications, 6(4), pp.462-473.

[21] Sharma, S. and Crossler, R.E., 2014. Disclosing too much? Situational factors affecting information disclosure in social commerce environment. Electronic Commerce Research and Applications, 13(5), pp.305-319.

[22] Yang, Z., Shi, Y. and Yan, H., 2016. Scale, congestion, efficiency and effectiveness in e-commerce firms. Electronic Commerce Research and Applications, 20, pp.171-182.

[23] Hemn Barzan Abdalla, Lu Zhen, Zhang Yuantu, 2021. A New Approach of e-Commerce Web Design for Accessibility based on Game Accessibility in Chinese Market. International Journal of Advanced Computer Science and Applications, 12, pp.1-8. 